\title{
Centrifuge modelling of a laterally cyclic loaded pile
}

\author{
Klinkvort, Rasmus Tofte; Leth, Caspar Thrane; Hededal, Ole
}

Published in:

Physical Modelling in Geotechnics

Publication date:

2010

Document Version

Publisher's PDF, also known as Version of record

Link back to DTU Orbit

Citation (APA):

Klinkvort, R. T., Leth, C. T., \& Hededal, O. (2010). Centrifuge modelling of a laterally cyclic loaded pile. In Physical Modelling in Geotechnics (Vol. 7, pp. 959-964). Taylor \& Francis.

\section{General rights}

Copyright and moral rights for the publications made accessible in the public portal are retained by the authors and/or other copyright owners and it is a condition of accessing publications that users recognise and abide by the legal requirements associated with these rights.

- Users may download and print one copy of any publication from the public portal for the purpose of private study or research.

- You may not further distribute the material or use it for any profit-making activity or commercial gain

- You may freely distribute the URL identifying the publication in the public portal

If you believe that this document breaches copyright please contact us providing details, and we will remove access to the work immediately and investigate your claim. 


\title{
Centrifuge modelling of a laterally cyclic loaded pile
}

\author{
R.T. Klinkvort, C.T. Leth \& O. Hededal \\ Technical University of Denmark, Copenhagen, Denmark
}

\begin{abstract}
A total number of 9 monotonic and 6 cyclic centrifuge tests on laterally loaded piles in very dense, dry sand was performed. The prototype dimensions of the piles were 1 meter in diameter and penetration depths varying from 6 to 10 meters. The static tests were used to investigate the initial subgrade reaction modulus and as a reference for cyclic tests. For the cyclic tests the accumulation of deflections and the change in secant stiffness of the soil from repetitive loading were investigated. From all the tests carried out accumulations of deflections were seen. From the centrifuge tests it was seen that no reduction occurs of the overall bearing capacity and that deflections accumulate due to cyclic loading. This paper presents test results and discusses the effects from load eccentricity and effects from cyclic loading with focus on accumulations of the deflection and the change in secant stiffness.
\end{abstract}

\section{INTRODUCTION}

Over the last decades there has been an increasing focus on alternative sustainable energy. One of these alternative sources is energy from wind turbines. The most widely used foundation method for offshore wind turbines is single large diameter tubular steel piles commonly denoted monopiles. The monopile design has been used in Denmark at the wind turbine parks at Samsø and Horns Rev. The design of monopiles is commonly based on the theory of laterally loaded piles. This theory relies on empirical data originated from the oil and gas industry, Reese \& Matlock (1956) \& McClelland \& Focht (1958). The design for the lateral capacity is carried out by modelling the pile as a beam and the soil as a system of uncoupled springs, known as a Winkler model. The springs are described by $p-y$ curves which defines the load displacement relationship for the interaction between soil and pile, API (1993). The formulation of these curves was originally calibrated to slender piles, but is today even used for design of large diameter monopiles. However, the monopiles used for wind turbine foundations act as stiff piles. Therefore it is relevant to investigate the behavior of stiff piles in more detail. The current test program comprises piles with a prototype diameter of $1 \mathrm{~m}$ and penetration depths up to $10 \mathrm{~m}$ and is intended to investigate the behavior of the larger monopiles used offshore today.

\section{SCOPE OF WORK}

Two major loads act on an offshore wind turbine. One due to the wind at the top of the wind turbine and one due to the waves and ice at sealevel. The purpose of the research carried out is to investigate the pile behavior when changing the location of force resultant and the penetration depth. The investigation will for the static tests focus on the initial stiffness of the pile-soil response. The cyclic tests will focus on the gradual change in secant stiffness and the accumulation of deflection as a function of the number of load cycles.

\section{DESIGN METHODOLOGY}

The method for sand presented here is the one used in API (1993), which is based on the formulation proposed by Murchison \& O’Neill (1984).

The p-y relationship for sand is typically approximated by

$p=A \cdot p_{u} \tanh \left[\frac{k \cdot X}{A \cdot p_{u}} y\right]$

The value $k$ represents the initial modulus of subgrade reaction and $X$ is the distance to soil surface. $p_{u}$ is the ultimate soil resistance and is found using plasticity theory. $A$ is an empirical constant which is used to fit the test results with theory. For static loading $A=\left(3.0-\frac{0.8 X}{D}\right) \geq 0.9$. For cyclic loading $A=0.9$

The initial stiffness of the p-y relationship can be found if $p$ is differentiated with respect to $y$,

$E_{p y, i n i}=\frac{\partial}{\partial y}\left[A \cdot p_{u} \tanh \left(\frac{k \cdot X}{A \cdot p_{u}} y\right)\right]_{y=0}=k \cdot X$ 
From Equation 2 it can be seen that the design codes uses a initial stiffness of the p-y relationship which is increasing linearly with depth.

\section{EXPERIMENTS}

The centrifuge test program was performed on solid steel piles with a diameter $d=16 \mathrm{~mm}$ and penetration depths between $96-160 \mathrm{~mm}$. The gravity field was increased to obtain a scaling factor of approximately $N=62.5$. This resulted in prototype piles with a diameter of $d=1 \mathrm{~m}$ and penetration lengths between $L=6-10 \mathrm{~m}$.

The different definitions are shown in Figure 1. The test program for the static and cyclic tests can be seen in Table 1. Here $L$ is the penetration depth, $e$ is the load eccentricity, while $m$ and $c$ indicate monotonic and cyclic test, respectively. All static and cyclic tests were performed in dry Fontainebleau sand. Leth et al. (2008) has collected classification parameters for the Fontainebleau sand which can be seen in Table 2 . The average grain
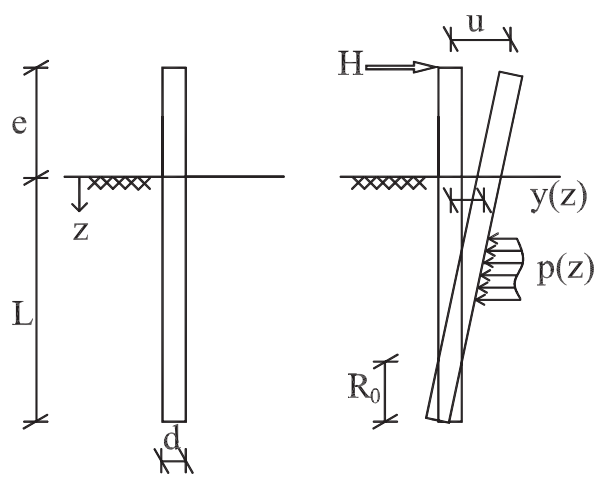

Figure 1. Sketch of pile.

Table 1. Test program for the centrifuge tests.

\begin{tabular}{llll}
\hline$e \backslash L$ & $6 d$ & $8 d$ & $10 d$ \\
\hline $2.5 d$ & $\mathrm{~m} \mathrm{c}$ & $\mathrm{m} \mathrm{c}$ & $\mathrm{m} \mathrm{c}$ \\
$4.5 d$ & $\mathrm{~m} \mathrm{c}$ & $\mathrm{m} \mathrm{c}$ & $\mathrm{m}$ \\
$6.5 d$ & $\mathrm{~m} \mathrm{c}$ & $\mathrm{m}$ & $\mathrm{m}$ \\
\hline
\end{tabular}

Table 2. Classification parameters for the Fontainebleau sand.

\begin{tabular}{lll}
\hline Specific gravity of particles & $G_{s}$ & 2.646 \\
Minimum void ratio & $e_{\min }$ & 0.548 \\
Maximum void ratio & $e_{\max }$ & 0.859 \\
Average grain size & $d_{50}$ & 0.18 \\
Coefficient of uniformity & $C_{\mathrm{u}}$ & 1.6 \\
\hline
\end{tabular}

size of the Fontainebleau sand is $0.18 \mathrm{~mm}$. The test piles have a diameter of $16 \mathrm{~mm}$. This leads to a "model diameter/grain size diameter" ratio of $16 / 0.18=88$. This ratio should be large enough to avoid particle size effects when applying the artificial gravity field according to the observations described in Fuglsang \& Ovesen (1988).

A spot pouring hopper (SPH) was used for the preparation of the sand sample. This equipment was developed according to a setup described in Huei-Tsyr et al. (1998). Due to the geometry of the container and pile the sand is prepared using a circular travelling loop as described in Zhao et al. (2006). CPT tests have been carried out to validate the pouring method. All these CPT tests showed the soil sample has a good homogeneity in the container, Gottlieb et al. (2005). After the sand is prepared, the pile is installed at $1 \mathrm{~g}$.

A total of 15 centrifuge tests have been performed: nine monotonic and six cyclic. For all the tests the relative density was found to vary in the range 0.9-0.95 The relative densities are calculated by measuring the weight and the volume of the sand sample. The average value for both the static and cyclic tests is $I_{D}=0.924$ and a void ratio of $e=0.57$. It is assessed that the small variation of the density not will affect the results significantly.

\subsection{Monotonic tests}

The force and deflection are normalized to facilitate comparison between the different tests. The normalized force is defined as

$P=\frac{H}{\gamma \cdot d^{3}}$

and normalized deflection is defined as

$U=\frac{u}{d}$

In Figure 2 the observation on the change between load with an eccentricity on $6.5 d$ and $4.5 d$ or $2.5 d$ is clear. The tendency is that for load eccentricity of $6.5 d$ and $4.5 d$ the normalized lateral bearing capacity is nearly identical. This indicates that a change in failure mechanism occurs.

More tests have to be conducted in order to clarify how the load eccentricity and pile penetration depth affects the pile-soil failure mechanism.

The design codes assume a linear increase in the initial stiffness with depth as indicated by Equation 2. Several authors have, however, proposed alternative distributions e.g. Lesny \& Wiemann (2006) and Haahr (1989). Therefore the increase in initial stiffness is investigated further. 

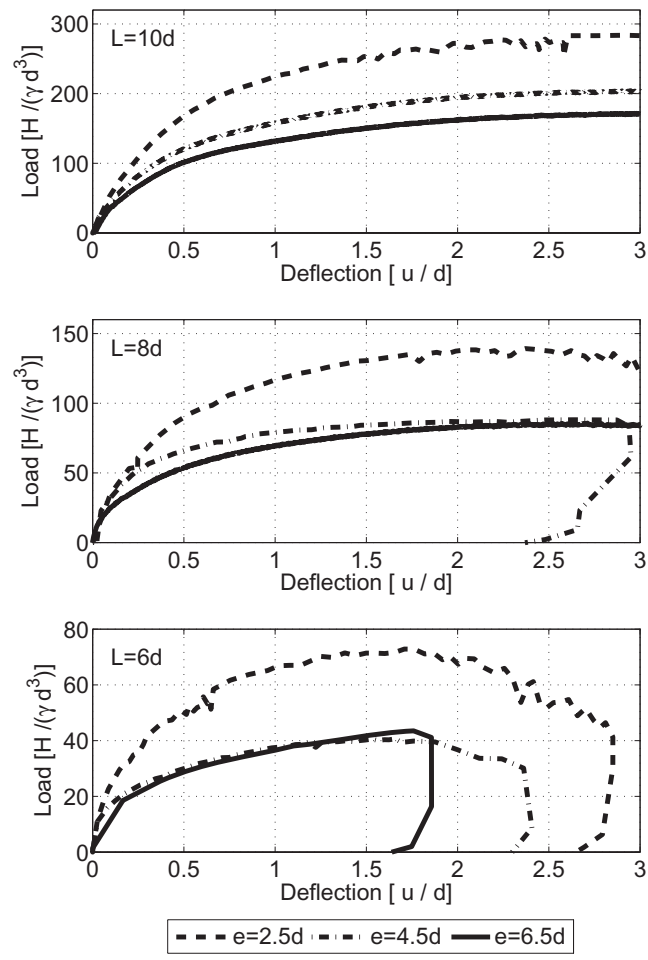

Figure 2. Normalized plot with the nine monotonic tests.

At initial loading the pile is assumed to behave as a rigid pile and only elastic deformations occur in the sand. This implies that the pile deflection can be described knowing the pile head deflection and the rotation.

$y(z)=u-\theta(e+z)$

In the present setup, the pile may be assumed to behave rigidly if, according to Equation 6 by Poulos \& Hull (1989), the stiffness of the sand is less than $E_{s}=100 \mathrm{MPa}$.

$1.48\left(\frac{E_{p} I_{p}}{E_{s}}\right)^{\frac{1}{4}}<L_{\text {inter }}<4.44\left(\frac{E_{p} I_{p}}{E_{s}}\right)^{\frac{1}{4}}$

The soil reaction on the pile can be described as an initial stiffness times the deflection of the pile.

$p(z)=-E_{p y, \text { ini }}(z) y(z)$

The initial stiffness may be assumed to have a nonlinear variation with depth as e.g. given in Equation 8 . Here $n=1$ corresponds a linear distribution and $n=0.5$ corresponds to a parabolic distribution.
$E_{p y, i n i}\left(\frac{z}{d}\right)=A_{n} \cdot\left(\frac{z}{d}\right)^{n}$

Considering moment and horizontal equilibrium, the constant $A_{n}$ can be found to be

$$
A_{n}=\left\{\begin{array}{l}
\frac{144+384\left(\frac{e}{L}\right)+288\left(\frac{e}{L}\right)^{2}}{8 L} \frac{H}{u} \frac{d}{L}, n=1 \\
\frac{75+210\left(\frac{e}{L}\right)+175\left(\frac{e}{L}\right)^{2}}{8 L} \frac{H}{u} \sqrt{\frac{d}{L}}, n=0.5
\end{array}\right.
$$

For the nine static tests the constant An has been calculated using both relations for the development of the initial stiffness. The applied force has been found for the entire test series at an initial deflection of $u / d=0.1$. The results are presented in Table 3. It must be expected that the soil has the same subgrade modulus for all the tests. Therefore, considering the smaller variation of the constant $A_{n}$ for $n=0.5$, it is assessed that the parabolic distribution gives a better description of the initial subgrade modulus. This parabolic distribution is also observed by Haahr (1989) and a distribution with $n=0.6$ is observed by Lesny \& Wiemann (2006).

The design codes prescribe a linear distribution of the initial subgrade reaction. This distribution was found using data from tests on long slender piles. For long slender piles only deformation on the upper part of the pile is seen and it is therefore only in the upper part of the pile data can be withdrawn. The tendency according to initial stiffness seen in the upper part is then extrapolated to the lower part. A linear distribution and a parabolic distribution may be nearly identical in the upper part of the pile but yield large differences in the lower part. The effects on a long slender pile from

Table 3. Calculated subgrade reaction modulus for the nine monotonic tests.

\begin{tabular}{llll}
\hline$L$ & $e$ & $A n=1$ & $A n=0.5$ \\
{$[d]$} & {$[d]$} & {$[k P a]$} & $\begin{array}{l}A k P] \\
{[k P a}\end{array}$ \\
\hline 10 & 2.5 & 3962 & 6883 \\
10 & 4.5 & 3994 & 7105 \\
10 & 6.5 & 4845 & 8753 \\
8 & 2.5 & 4851 & 7603 \\
8 & 4.5 & 4908 & 7883 \\
8 & 6.5 & 5211 & 8595 \\
6 & 2.5 & 6532 & 8972 \\
6 & 4.5 & 6015 & 8466 \\
6 & 6.5 & 6268 & 8943 \\
\hline
\end{tabular}


assuming a wrong distribution will therefore not be critical. This is not the case for a short rigid pile.

Sørensen et al. (2009) compared FLAC ${ }^{3 D}$ calculations with the p-y approach recommended by design codes. They adopted a distribution proposed by Lesny \& Wiemann (2006) which is identical with Equation 8 with $n=0.6$. They observed that the use of this distribution gave a better fit to the results from the three dimensional numerical model, but more tests have to be conducted in order to clarify the distribution of the initial subgrade reaction.

In Table 4 different values of initial subgrade modulus for dense dry sand is presented. For these values proportional distribution is expected. From this table it can be seen that the values proposed by API (1993) and Reese \& Impe (2001) are much larger than the values found by Remaud (1999).

Some of the tests presented here were numerically modelled using the Winkler method by Klinkvort (2009). The best fit to the monotonic curves was done using an initial subgrade modulus of $k=2.7 \mathrm{MN} / \mathrm{m}^{3}$.

This study and the study by Remaud (1999) both used centrifuge modelling where the deflection is scaled with a factor of $N$ and the force is scaled with a factor of $N^{2}$. The scaling factors are found using dimensional theory. More tests have to be conducted in order to clarify results from centrifuge modelling in order to determine the magnitude and distribution of the initial stiffness.

\subsection{Cyclic tests}

In the cyclic tests the pile was subjected to 100 force controlled load cycles. To investigate the influence from previous loading three of the tests were performed in three phases. The first phase with large cycles, second phase with smaller cycles and the third phase with cycles equal to cycles in the first phase. To investigate the effects from cyclic loading this paper uses methods described in LeBlanc (2009) to account for accumulation of deflections and the change in secant stiffness.

A set of load characteristic constant are used to describe the cyclic loading. The load characteristics are denoted $\zeta_{b}$ and $\zeta_{c}$. They are determined as shown in Equation 10.

Table 4. Comparison of modula of initial subgrade reaction.

\begin{tabular}{lc}
\hline & $k_{p y}\left[M N / m^{3}\right]$ \\
\hline API (1993) & 83 \\
Reese \& Impe (2001) & 61 \\
Remaud (1999) & 8 \\
\hline
\end{tabular}

$\zeta_{h}=\frac{H_{\max }}{H_{\text {static }}} \zeta_{c} \frac{H_{\min }}{H_{\text {max }}}$

Here $H_{\max }$ and $H_{\min }$ are the maximum and minimum applied force in the cyclic loading. $H_{\text {static }}$ is the maximum bearing capacity found from the static test. $\zeta_{b}$ describes how close the cycles are carried out to the static bearing capacity. $\zeta_{b}=1$ is therefore cycles carried out to the maximum bearing capacity. $\zeta_{c}$ describes the direction of the loading. For one-way loading $\zeta_{c}=0$ and for two-way loading $\zeta_{c}=-1$.

In all of the 6 cyclic tests, accumulation of the deflection was seen. The best fit in all the tests was with a power fit as proposed by Long \& Vanneste (1994) and LeBlanc (2009), cf. Equation 11.

$$
\Delta u(N)=u_{0} \cdot N^{\delta}
$$

Here $u_{0}$ is the accumulated deflection at the first cycle and $\delta$ is an empirical coefficient which control the shape of the curve. The accumulated deflection for a given cycle is defined as the average value for the cycle.

A small increase in secant stiffness was observed for the first 100 cycles for all the tests. The best fit to the change in secant stiffness was done with a exponential function cf. Equation 12.

$\kappa(N)=\kappa_{0} \cdot e^{\kappa N}$

$\kappa_{0}$ describes the initial secant stiffness in the first cycle. $\kappa$ describes the change in secant stiffness.

Figure 3 shows the results for cyclic testing on the pile with a load eccentricity $e=2.5 d$ and a penetration depth $L=10 d$. This way of analyzing the cyclic tests has been done for all the performed tests.

As it can be seen from Figure 3, the determination of the secant stiffness and accumulation of the deflection involves a great scatter of data. This was also reported by LeBlanc (2009). This is to a some extent attributed the fact that measurements involves differences of small displacements.

The results from the cyclic tests are shown in Table 5. No clear relationship for the coefficients can be seen concerning load eccentricity and penetration depth. Neither do the results show any clear correlation to the loading characteristic constants $\zeta_{b}$ and $\zeta_{c}$. Table 5 shows that the loading characteristic constants $\zeta_{b}$ and $\zeta_{c}$ has a large difference from test to tests. Therefore it is not possible from the performed test to conclude on the effect of the loading eccentricity and pile penetration, and further tests need to be conducted.

It seems like the development of the secant stiffness can be expressed in a more simple form 

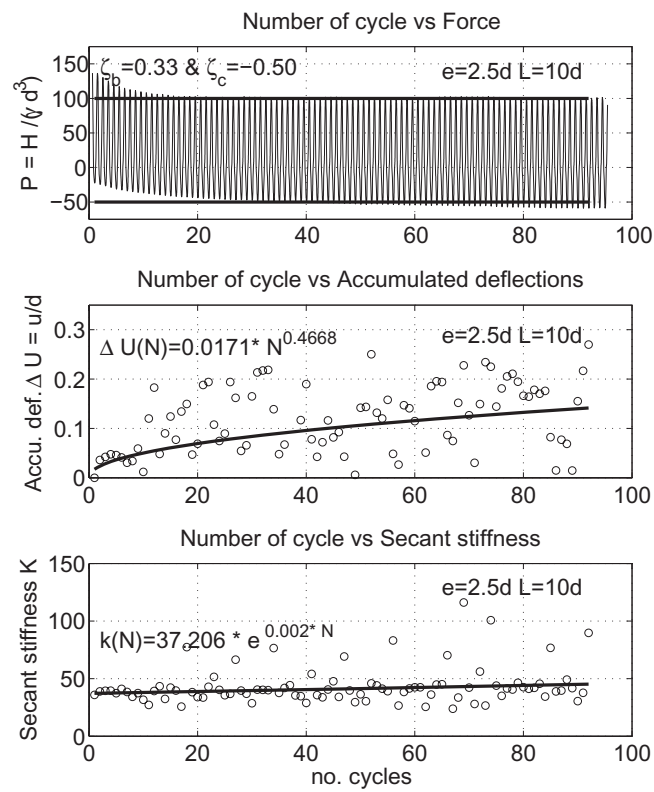

Figure 3. Displacements difference versus secant stiffness for cyclic test $e=2.5 \& L=10 d$.

Table 5. Dimensionless results from the cyclic testing.

\begin{tabular}{rlllllll}
\hline$L$ & $e$ & $\zeta_{b}$ & $\zeta_{c}$ & \multicolumn{1}{c}{$\Delta u_{0}$} & \multicolumn{1}{l}{$\delta$} & \multicolumn{1}{c}{$\kappa_{0}$} & $\kappa$ \\
\hline 10 & 2.5 & 0.3 & -0.5 & 0.02 & 0.46 & \multicolumn{1}{c}{37} & 0.002 \\
10 & 4.5 & 0.3 & -0.8 & 0.04 & 0.11 & 6.6 & 0.018 \\
10 & 6.5 & 0.7 & -0.6 & 0.02 & 0.72 & 11.4 & 0.003 \\
8 & 4.5 & 1.0 & -0.6 & 0.1 & 0.31 & 4.1 & 0.006 \\
8 & 6.5 & 0.8 & -0.9 & 0.1 & 0.01 & 2.2 & 0.000 \\
6 & 6.5 & 0.6 & -0.8 & 0.1 & 0.45 & 5.7 & 0.004 \\
\hline
\end{tabular}

than proposed in Equation 12. In the last column in Table $5 \kappa$ is shown. For all the tests except the test $e=4.5 L=10 d$, this value is very small. This indicates that the change in secant stiffness is very small and it may be sufficient to described the change in secant stiffness in a linear fashion. For three of the cyclic test $(e=4.5 d L=8 d, e=4.5 d$ $L=6 d \& e=6.5 d L=6 d$ ) new cyclic loading was done after the first 100 cycles. The new cyclic testing was done with a smaller amplitude than the first. Only in the test with a load eccentricity of $4.5 d$ a decrease in the secant stiffness was seen. It must be expected that when performing a loading series with a smaller amplitude the secant stiffness will decrease as long as no equilibrium in the cyclic loading is found. When the pile has compacted the sand around the pile in a constant manner, the cyclic behavior will stabilize and the secant stiffness will increase. When performing cyclic loading

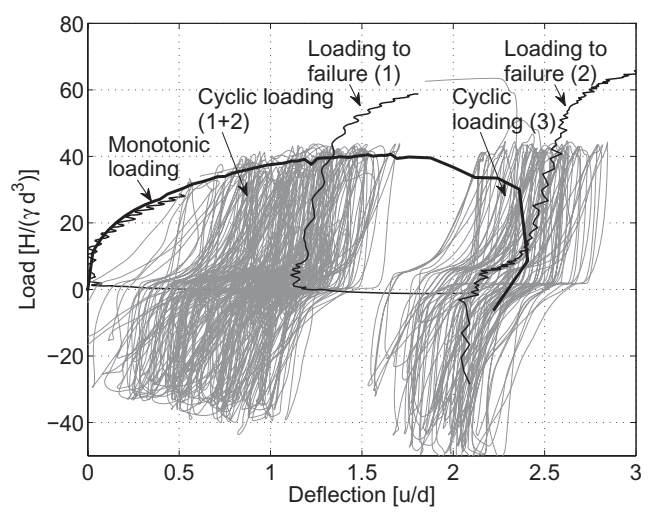

Figure 4. Normalized plot for the cyclic test $e=4.5 d \&$ $L=6 d$.

again with a larger amplitude the secant stiffness in all the tests shows an increase.

An example of a cyclic tests series is shown in Figure 4. The plot contains two different tests; the monotonic test and the corresponding cyclic test series. The cyclic test series contains of first 100 cycles, followed with 100 cycles with smaller amplitude. After these cycles, the pile is loaded to failure and unloaded, then 100 cycles are applied again with a monotonic loading to failure at the end.

The pile is loaded to failure twice and it can be seen that the pile reaches a higher bearing capacity than the monotonic test. Cyclic loading is handled in the design codes by a reduction of the static soil resistance. This leads to a reduction of the bearing capacity and the pile - soil stiffness. These tests indicate that no reduction of the bearing capacity will occur.

From the cyclic load series it can also be seen that the secant stiffness increases for the cyclic loading in the investigated cases.

\section{CONCLUSIONS}

The monotonic tests revealed a relationship between the lateral bearing capacity of the pile and the load eccentricity. This indicates that there are different failure mechanisms for piles with large load eccentricity and piles with smaller load eccentricity. In practise this may be of importance for offshore wind turbines subjected to a combination of wind load from the rotor acting $60-100 \mathrm{~m}$ above seabed level and wave forces acting relatively closer to the seabed.

The centrifuge modelling indicates that using the design code recommendations to generate $\mathrm{p}-\mathrm{y}$ curves led to a overestimation of the pile-soil 
stiffness. Due to this observation it is believed that the recommendations to generate the distribution and magnitude of the initial subgrade modulus should be changed. Further research is needed to gain knowledge about this.

From all the cyclic tests carried out, accumulations of deflections were seen. The secant stiffness of every cycle was measured revealing that the cyclic loading led to an increase in secant stiffness. From the centrifuge tests it was clearly seen that no reduction of the bearing capacity of dry sand occurs due to cyclic loading.

It seems like the influence of the location of the applied force on a laterally loaded pile was most critical for the monotonic bearing capacity. It is believed that this also affects the accumulations of deflection and the change in secant stiffness but it was not clearly seen in this research.

\section{REFERENCES}

API 1993. Recommended Practice For Planning, Designing and Construction Fixed Offshore Platforms-Load and Resistance Factor Design. American Petroleum Institute.

Fuglsang, L.D. \& Ovesen, N.K. 1988. The application of the theory of modelling to centrifuges studies. Balkema, Rotterdam.

Gottlieb, S., Klinkvort, R.T., Petersen, J. \& Christensen, L.K. 2005. Calibration and the use of mini-cpt. Student report, Technical University of Denmark (in Danish).

Haahr, F. 1989. Interaction between latterally laoded model piles in sand. Ph.D. thesis, Technical University of Denmark. (in Danish).

Huei-Tsyr, C., Chung-Jung, L. \& Hung-Wen, C. 1998. The travelling pluvation apparatus for sand specimen preparation. Centrifuge 98 1: p. 143-148.

Klinkvort, R.T. 2009. Laterally loaded piles - centrifuge and numerically modelling. Master's thesis, Technical University of Denmark.

LeBlanc, C. 2009. Design of Offshore Wind turbine Support Structures. Ph.D. thesis, Aalborg University.
Lesny, K. \& Wiemann, J. 2006. Finite-element-modelling of large diameter monopiles for offshore wind energy converters. In Geo Congress.

Leth, C.T., Krogsbøll, A., \& Hededal, O. 2008. Centrifuge facilities at danish technical university. In 15th Nordic Geotechnical Meeting.

Long, J.H. \& Vanneste, G. 1994. Effects of cyclic lateral loads on piles in sand. Journal of Geotechnical Engineering 120: 225-244.

McClelland, B. \& Focht, J.A. 1958. Soil modulus for laterally loaded piles. Journal of the soil mechanics and foundations division-Proceedings of the American Society of Civil Engineers: 1-22.

Murchison, J.M. \& O'Neill, M.W. 1984. Evaluation of p-y relationships in cohesionless soils. In Proc., Symposium of Analysis and Design of Pile Foundations, ASCE, San Fransisco, 174-191.

Poulos, H. \& Hull, T. 1989. The role of analytical geomechanics in foundation engineering. Foundation Engineering: Current principles and Practices, ASCE, Reston 2: 1578-1606.

Reese, L.C. \& Impe, W.F.V. 2001. Single Piles and Pile Groups Under Lateral Loading. A.A. Balkema.

Reese, L.C. \& Matlock, H. 1956. Non-dimensional solutions for laterally loaded piles with soil modulus assumed proportional to depth. Proceedings of the 8th Conference on Soil Mechanics: 1-41.

Remaud, D. 1999. Pieux sous charges laterales: Etude Ex-perimentale de l'effect de groupe. Ph.D. thesis, Ecole Centrale de Nantes. (in French).

Sørensen, S., Brødbæk, K.T., Møller, M., Augustesen, A.H. \& Ibsen, L.B. 2009. Evaluation of the loaddisplacement relationships for large-diameter piles in sand. In Proceedings of the Twelfth International Conference on Civil, Structural and Environmental Engineering Computing.

Zhao, Y., Gafar, K., Elshafie, M., Deeks, A., Knappett, J. \& Madabhushi, S. 2006. Calibration and use of a new automatic sand pourer. In Physical modelling in Geotechnics, 6th ICPMG'06, p. 265-270. 